\title{
Los Consejos de Justicia Autonómicos. El Consejo de Justicia Andaluz
}

\author{
Miguel Ángel Pareja Vallejo \\ Magistrado, Doctor en Derecho y \\ Máster en Derecho Autonómico y Local.
}

\begin{abstract}
SUMARIO: I. INTRODUCGIÓN. II. ANTEGEDENTES DE LOS CONSEJOS DE JUSTICIA AUTONÓMICOS. III. EL CONSEJO DE JUSTICIA DE ANDALUCÍA. 1. Introducción. 2. Regulación Estatutaria. 3. Naturaleza jurídica. 4. El Gobierno del Poder Judicial en la Constitución. 5. Posición del Tribunal Constitucional sobre el Consejo de Justicia de Cataluña. 6. El caso andaluz. 7. Propuestas. IV. CONCLUSIONES. V. BIBLIOGRAFÍA.
\end{abstract}

\section{RESUMEN}

El objetivo de este trabajo es analizar los Consejos de Justicia autonómicos y, en particular, el Consejo de Justicia de Andalucía. Por último, el autor ofrece una serie de propuestas para una mejor integración entre el Poder Judicial y las Comunidades Autónomas.

Palabras clave: Poder Judicial, Comunidades Autónomas, Consejos de Justicia autonómicos.

ABSTRACT

The aim of this work is to analyse the Regional Justice Councils and, in particular, the Justice Council of Andalusía. Finally the author delivers a series of proposals for a better integration between the Judiciary and the regional governments.

Key words: Judiciary, “Autonomous Regions”, Regional Justice Councils.

\section{INTRODUCGIÓN}

Los Estatutos de Autonomía de nueva generación han creado los Consejos de Justicia autonómicos, siendo el primero de ellos el Estatuto de Autonomía de la 
Comunidad Valenciana, modificado mediante Ley Orgánica 1/2006 de 10 de abril, que dedica el Capítulo V del Título III a la Administración de Justicia, estableciendo su artículo 33.3 que "se crea el Consell de la Justicia de la Comunitat Valenciana. Una Ley de Les Corts determinará su estructura, composición, nombramiento y funciones dentro del ámbito de las competencias de la Generalitat en materia de administración de justicia en los términos que establece el presente Estatuto y de acuerdo con lo dispuesto en la Ley Orgánica del Poder Judicial.”

El siguiente Estatuto de Autonomía en crear un Consejo de Justicia Autonómico ha sido el Catalán, aprobado por Ley Orgánica 6/2006, de 19 de julio, de reforma del Estatuto de Autonomía de Cataluña, que se refiere en su Título III al Poder Judicial en Cataluña, preceptuando, en su redacción originaria, el artículo 97, que "el Consejo de Justicia de Cataluña es el órgano de gobierno del poder judicial en Cataluña. Actúa como órgano desconcentrado del Consejo General del Poder Judicial, sin perjuicio de las competencias de este último, de acuerdo con lo previsto en la Ley Orgánica del Poder Judicial."

A ellos les han seguido otros, como son el Estatuto balear (Ley Orgánica 1/2007, de 28 de febrero, de reforma del Estatuto de las Illes Balears, que dedica el Título VI al Poder Judicial, cuyo artículo 96 establece que "se crea el Consejo de Justicia de las Illes Balears. Una Ley del Parlamento de las Illes Balears determinará su estructura, composición, nombramientos y funciones en le ámbito de las competencias de las Illes Balears en materia de administración de justicia en los términos que establece este Estatuto y de acuerdo con la Ley Orgánica del Poder Judicial.”), el Estatuto andaluz (Ley Orgánica 2/2007, de 19 de marzo, de reforma del Estatuto de Autonomía para Andalucía, que se refiere en su Título V al Poder Judicial en Andalucía, cuyo artículo 144, que lo define como "el órgano de gobierno de la Administración de Justicia en Andalucía, de acuerdo con lo previsto en la Ley Orgánica del Poder Judicial.”), el Estatuto aragonés (Ley Orgánica 5/2007, de 20 de abril, de reforma del Estatuto de Autonomía de Aragón, que dedica el Capítulo I del Título IV al Poder Judicial, cuyo artículo 64 "crea el Consejo de Justicia de Aragón. Una Ley de las Cortes de Aragón determinará su estructura, composición, nombramientos y funciones dentro del ámbito de las competencias de la Comunidad Autónoma en materia de Administración de Justicia en los términos que establece el presente Estatuto y de acuerdo con lo dispuesto en la Ley Orgánica del Poder Judicial.”), el Estatuto castellano leonés (Ley Orgánica 14/2007, de 30 de noviembre, de reforma del Estatuto de Autonomía de Castilla y León, que se refiere en el capítulo V del Título II al Poder Judicial y si bien este Estatuto no llega a crearlo sino que prevé su posible creación al establecer su artículo 42 que "mediante ley de las Cortes de Castilla y León se podrá crear el Consejo de Jus- 
ticia de Castilla y León y establecer su estructura, composición y funciones dentro del ámbito de competencias de la Comunidad y de acuerdo con lo dispuesto en la legislación estatal."), habiendo sido el último el Estatuto extremeño (Ley Orgánica 1/2011, de 28 de enero, de reforma del Estatuto de Autonomía de la Comunidad Autónoma de Extremadura, que dedica su Título III al Poder Judicial en Extremadura, cuyo artículo 52 crea el Consejo de Justicia de Extremadura como "el órgano de participación institucional de la Comunidad Autónoma en el gobierno y la administración de la justicia en la Comunidad Autónoma, de acuerdo con lo que disponga la Ley Orgánica del Poder Judicial.”).

Ahora bien, el debate sobre la creación de los Consejos de Justicia no es nuevo, como no lo es tampoco la posibilidad de crear órganos de gobierno del Poder Judicial externos y de base territorial, al margen o diferentes de las Salas de Gobierno, habiéndose realizado diferentes propuestas sobre la conveniencia de su introducción en nuestro ordenamiento a nivel político y doctrinal. Por tanto con carácter previo es preciso entrar a enumerar los antecedentes de dichos Consejos.

\section{ANTEGEDENTES DE LOS CONSEJOS DE JUSTICIA AUTONÓMICOS}

El primer intento de creación se produjo durante la tramitación de la LO 1/1980, de 10 de enero, del CGPJ, donde el Grupo Parlamentario Socialista presentó una enmienda, la $\mathrm{n}^{\circ} 22$, al art. 1, en la que solicitaba que "en el ámbito de cada Tribunal Superior de Justicia o Audiencia Territorial se creará un Consejo Territorial con las competencias establecidas en la presente ley, sin perjuicio de lo que al respecto establezcan los Estatutos de Autonomía”. Dicha enmienda no fue finalmente discutida, sí lo fue la presentada por el Grupo Parlamentario Comunista, en la que solicitaba "la descentralización del gobierno del Poder Judicial que deberá quedar plasmada en los Consejos Territoriales", y como quiera que el constituyente lo que realmente quiso establecer es un gobierno del Poder Judicial único para todo el Estado, dicha enmienda fue rechazada por amplia mayoría parlamentaria ${ }^{1}$.

\footnotetext{
${ }^{1}$ En el mismo sentido puede leerse LÓPEZ JIMÉNEZ, J. "Especial referencia a los Consejos Autonómicos de Justicia y su constitucionalidad. El CGPJ: pasado, presente y futuro del órgano de gobierno de la administración de justicia." El Derecho Editores, Base de Datos Bibliográfica, Jurisprudencia, Jurisdicción Derecho Administrativo. Julio 2008.
} 
Aunque no llegó a ser discutido ni tramitado, si podemos encontrar otro antecedente en el texto del Borrador de Anteproyecto de LOPJ redactado por el Ministerio de Justicia durante la V Legislatura (1993/1996), que regulaba un Libro III, bajo la rúbrica "Del gobierno del Poder Judicial en las Comunidades Autónomas" en el que preveían los Consejos de Gobierno del Poder Judicial, configurándose como órganos de gobierno externo.

En noviembre de 1998, a instancias del Grupo Parlamentario Catalán, el Congreso de los Diputados tramitó una Proposición no de ley sobre medidas para afrontar la reforma de la Justicia. En ella, los debates se centraron en aspectos referentes al establecimiento de órganos y mecanismos de cooperación y colaboración entre el Consejo General del Poder Judicial y sus órganos territoriales (con competencia descentralizada o desconcentrada) y las Comunidades Autónomas, no haciéndose referencia alguna a la instauración de este tipo de órganos de gobierno judicial.

Fuera del ámbito parlamentario, el Consejo General del Poder Judicial en el Libro Blanco de la Justicia de 1997 , a propósito de "El gobierno de la Administración de Justicia" afirma que los artículos 122 y $149.1 .5^{\circ}$ de la Constitución, "impiden la existencia de órganos autonómicos del gobierno del Poder Judicial desvinculados o independientes del Consejo General", aunque "no excluyen que las potestades de gobierno del poder Judicial se ejerzan de forma desconcentrada en aquellas materias que, por referirse al gobierno interno de los jueces y Tribunales puedan asumir las Salas de gobierno de los Tribunales Superiores de Justicia, en todo caso, subordinadas al Consejo General del Poder Judicial."

La discusión sobre la creación de estos Consejos de Gobierno del Poder Judicial no fue tratada explícitamente en el documento de Pacto de Estado para la reforma de la Justicia de mayo de 2001. De tal manera que la Conferencia Sectorial de ese año, a propósito de las relaciones entre el Estado y las Comunidades Autónomas en materia de Justicia, se centraron básicamente en el modelo de oficina judicial, posteriormente reguladas en la LO 19/2003, de 23 de diciembre de modificación de la $\mathrm{LOPJ}^{3}$.

${ }^{2}$ El libro blanco de la fusticia aprobado por el Pleno de este Consejo General del Poder Judicial el 8 de septiembre de 1997, p. 147. http://www.icam.es/web3/docs/ob/libro_blanco_justicia.pdf [última visita 24 de noviembre de 2012].

${ }^{3}$ En el mismo sentido puede leerse el Voto Particular formulado por el Vocal del CGPJ LUIS AGUIAR DE LUQUE en relación al Anteproyecto de LO de modificación de la LO 6/1985, de 1 de ju- 
Posteriormente, en el Proyecto de Ley Orgánica de modificación de la Ley Orgánica del Poder Judicial en materia de justicia de proximidad y de Consejos de Justicia de diciembre de $2005^{4}$ se regulaban los Consejos de Justicia, configurándolos como órganos colegiados, cuya elección de sus miembros se atribuía a las Asambleas Legislativas de las comunidades autónomas por mayoría de tres quintos, insertados en la estructura del gobierno del Poder Judicial que sustituirían a las Salas de Gobierno de los Tribunales Superiores de Justicia y destinados a ejercer, de manera desconcentrada y subordinada al Consejo General del Poder Judicial, las funciones delegadas de gobierno que la propia ley establecía, así como las que los respectivos Estatutos de Autonomía les atribuyesen dentro de su ámbito competencial.

Por lo demás, los Estatutos de Autonomía de nueva generación han creado los denominados "Consejos de Justicia" en los términos recogidos en el epígrafe anterior.

Desde la doctrina también ha sido tratada la conveniencia o no de instaurar los Consejos de Justicia. Así ÁLVAREZ CONDE5 señalaba que "aunque esta posibilidad [la creación de los Consejos de Justicia autonómicos] puede producirse mediante la reforma de la LOPJ y es reclamada desde diversos sectores doctrinales, creemos que su instauración no debe considerarse con un carácter prioritario, ya que muchas de las competencias que tendrían estos Consejos Autonómicos corresponden hoy día a las Salas de Gobierno de los Tribunales Superiores de Justicia, no pareciendo su hipotética existencia resolver ningún problema."

lio, del Poder Judicial en materia de organización de la Administración de Justicia (Consejos de Justicia Autonómicos) y al que se adhieren los Vocales del CGPJ JUAN CARLOS CAMPO MORENO, Mª ÁNGELES GARCÍA GARCÍA, FÉLIX PANTOJA GARCÍA y FERNANDO SALINAS MOLINA, así como MONTSERRAT COMAS, quien a su vez formula un voto particular propio y complementario a éste. http://www.poderjudicial.es/stfls/cgpj/COMISI $\% \mathrm{C} 3 \% 93 \mathrm{~N} \% 20 \mathrm{DE} \% 20 \mathrm{ESTUDIOS} \% 20 \mathrm{E} \% 20 \mathrm{IN}-$ FORMES/INFORMES \%20DE\%20LEY/FICHERO/VOTO\%20PLENO \%20lopj\%20_3_1.0.0.pdf [última visita 28 de septiembre de 2012].

${ }^{4}$ Proyecto de Ley Orgánica de modificación de la Ley Orgánica 6/1985, de 1 de julio, del Poder Judicial, en materia de justicia de proximidad y Consejos de Justicia, aprobado por el Consejo de Ministros el 23 de diciembre de 2005 (Boletín Oficial de las Cortes Generales. Congreso de los Diputados. Serie A, núm. 71, de 27 de enero de 2006).

${ }^{5}$ ÁLVAREZ CONDE, E. "El ámbito competencial del Consejo General del Poder Judicial y las Comunidades Autónomas" Revista del Centro de Estudios Constitucionales Núm. 16. Septiembre-diciembre 1993, p. 11. 
Por su parte REQUERO IBÁÑEZ ${ }^{6}$ afirmaba que estos Consejos implicarían "multiplicar por diecisiete el viciado esquema de LOPJ, implicaría llevar la politización del gobierno judicial, no ya a su órgano central, sino a cada una de las regiones, dando lugar a una visión autonomizada de la Justicia, sujeta a los intereses políticos locales de todo signo a la par que implicaría no sólo suprimir el verdadero autogobierno de la Justicia, que es el desempeñado por los órganos de gobierno interno, sino politizar ese mismo ámbito."

Refiriéndose al Proyecto de LO de modificación de la LO 6/1985 del Poder Judicial de diciembre de 2005, al que antes se ha hecho mención, señalaba VEGAS TORRES ${ }^{7}$ que "parece previsible que, igual que viene sucediendo con la designación parlamentaria de los vocales del CGPJ, la designación de estos nuevos miembros de los Consejos de Justicia se vea envuelta en polémicas sobre el perfil político de los candidatos, con el daño consiguiente a la imagen de la Justicia."

A favor de la creación de los Consejos de Justicia Autonómicos, señalaba XIOL RÍOS ${ }^{8}$ que "podrían ver la luz como Delegaciones Territoriales del CGPJ, que no vendrían a reemplazar el papel del Consejo General del Poder Judicial pero que contarían con cierta participación en el mismo, dejando la presidencia de dichas Delegaciones al Presidente del Tribunal Superior de Justicia y quedando relegado al Reglamento la composición de las mismas."

Para HERNÁNDEZ GÓMEZ9 “en cualquier caso, y para salir al paso de los detractores de éstos órganos que alegan la descentralización de la Justicia y la pérdida de la Unidad Jurisdiccional, entendemos que son órganos de gobierno de aspectos accesorios de la prestación de la función jurisdiccional, que en nada afectan al ejercicio de la Potestad Jurisdiccional y a la exigible independencia de la que constitucional y legalmente gozan los integrantes del Po-

${ }^{6}$ REQUERO IBÁÑEZ, J., "El Gobierno Judicial y el Consejo General del Poder Judicial” Fundación para el Análisis y Estudios Sociales. Papeles de la Fundación No 28, Madrid, 1996. http://www.fundacionfaes.org/record_file/filename/284/00297-00.pdf [última visita 3 de octubre de 2012].

7 VEGAS TORRES, J., "Consejos de Justicia y Justicia de Proximidad" Revista De derecho Procesal, 2006, http://www.jaimevegas.es/cms/downloads/2006_Consejos\%20de\%20Justicia\%20y\%20justicia $\% 20$ de $\% 20$ proximidad.pdf [última vista 3 de octubre de 2012].

${ }^{8}$ XIOL RÍOS, J. "El Poder Judicial y su Consejo General en el Estado Social y Democrático de Derecho" Premios Poder Fudicial (I), CGPJ, 1986, pp. 116 y ss.

${ }^{9}$ HERNÁNDEZ GÓMEZ, I. "Estatuto de Autonomía y Administración de Justicia en Canarias" Revista de la Facultad de Ciencias furídicas No 10/1, 2005/06, p. 104. 
der Judicial a la hora de ejercitar, de manera exclusiva y excluyente, el mandato constitucional de juzgar y hacer ejecutar lo juzgado a través de las resoluciones judiciales."

Posteriormente, una vez publicado el Estatuto Andaluz, DEL RÍO MUÑOZ ${ }^{10}$ escribía que "también es posible estimar, en una crítica de fondo, que la creación de estos órganos no es conveniente por que puede crear disfuncionalidades y diferencias de apreciación e incluso que, económicamente su existencia no se justifica por el incremento de gasto que supondría, lo que se contrapone a las ventajas de que también en el Poder Judicial se refleje la estructura territorial del Estado y los beneficios de una mayor cercanía en la toma de decisiones, pero lo que no cabe duda es de la constitucionalidad de su creación."

Tampoco le cabe duda de su constitucionalidad a BALLESTER CARDELL" ${ }^{11}$ para quien, "las regulaciones estatutarias que acabamos de transcribir no plantean problemas propiamente de constitucionalidad y, por consiguiente, son perfectamente incardinables en el modelo constitucional."

En consecuencia, señala GOLOMER HERNÁNDEZ12 que "la valoración que debe hacerse en su conjunto del sistema de reparto de competencias relativas al gobierno de la Administración de Justicia en Andalucía entre el Consejo andaluz de justicia y el Consejo General del Poder Judicial debe ser positiva. Dado que el propio sistema de reparto se basa en reconocer que las competencias y facultades relativas al gobierno de la justicia corresponden al CGPJ por reserva expresa del artículo 122.2 de la CE, y que las competencias previstas para el Consejo andaluz serán ejercitables de acuerdo a la previsión que sobre ellas contenga la LOPJ. En otras palabras, es la LOPJ la que determina los límites y características que puede llegar a alcanzar el Consejo de Justicia en relación con el ejercicio de una concreta competencia o facultad."

${ }^{10}$ DEL RÍO MUÑOZ, F. "El Poder Judicial y reformas estatutarias. El nuevo Estatuto de Autonomía de Andalucía." Centro de Estudios Andaluces. Núm. 22, p. 14.

${ }^{11}$ BALLESTER CARDELL, M., "Las reformas de los Estatutos de Autonomía y el Poder Judicial. La progresiva adaptación de la administración de justicia al estado de las autonomías." http://www.acoes.es/pdf $/$ la $\% 20$ reforma $\% 20$ de $\% 201$ os $\% 20$ estatutos $\% 20$ de $\% 20$ autonoma $\% 5$ B $1 \% 5$ D.def..pdf, [última vista 30 de septiembre de 2012].

${ }^{12}$ COLOMER HERNÁNDEZ, I. "El Consejo de Justicia de Andalucía." En MANUEL JOSÉ TEROL BECERRA et alii, Comentarios al Estatuto de Autonomía para Andalucia, Tirant lo Blanch, Valencia, 2009, p. 472. 


\section{EL GONSEJO DE JUSTICIA DE ANDALUCÍA}

\section{Introducción.}

La Ley Orgánica 6/1981, de 30 de diciembre, de Estatuto de Autonomía para Andalucía, vigente hasta el 20 de marzo de 2007, dedicaba el Título III a la Administración de Justicia (artículos 47 a 53) ${ }^{13}$, siendo dicha regulación respetuosa con el bloque de constitucionalidad y con las competencias reservadas por la Constitución al Estado, referidas a la Administración de justicia (artículo 149.1.5 de la CE) y a la legislación procesal (artículo 149.1.5 a de la CE), y, es que como señala DEL RÍO MUÑOZ14 "la verdad es que en materia de Administración de Justicia queda poco margen para su inclusión en un Estatuto de Autonomía. El artículo 149.1.5 C.E. reserva a la competencia estatal la Administración de Justicia a lo que se une la regulación del Poder Judicial en el Título VI, artículos 117 a 127”.

Sin embargo, el Estatuto vigente, dedica el Título V al Poder Judicial en Andalucía, el cual se estructura en tres Capítulos, el Capítulo I dedicado al Tribunal Superior de Justicia de Andalucía (artículos 140 a 143), el Capítulo II regula el Consejo de Justicia de Andalucía y se forma de un solo artículo, el 144, y por último el Capítulo III, el más extenso, se refiere a las competencias de la Junta de Andalucía en materia de Administración de Justicia, artículos 145 a 155.

En este trabajo tan solo vamos a analizar el Capítulo II, no obstante, no puede comprenderse la regulación del Consejo de Justicia Andaluz sin hacer referencia a la regulación efectuada por el Estatuto Catalán, ya que el andaluz va de la mano de éste habiéndose dado a muchos de sus preceptos idéntica o semejante redacción ${ }^{15}$.

\footnotetext{
${ }^{13}$ Sobre el proceso de construcción de la Comunidad Autónoma y sus instituciones Vid. CLAVERO ARÉVALO, M. "Andalucía veinticinco años del Estatuto de Autonomía" Administración de Andalucía: revista andaluza de administración pública, Núm. 1, 2003, pp. 23-28.

${ }^{14}$ DEL RÍO MUÑOZ, F., "El Poder Judicial y reformas estatutaria..." Op. Cit., p. 13.

${ }^{15}$ Así se puede observar de la propia sistemática y contenido del actual Estatuto de Autonomía para Cataluña que ha sido aprobado mediante Ley Orgánica 6/2006, de 19 de julio, de reforma del Estatuto de Autonomía de Cataluña, el cual dedica el Título III al Poder Judicial en Cataluña, que se estructura en tres Capítulos, el primero sobre el Tribunal Superior de Justicia y el Fiscal o la Fiscal Superior de Cataluña (artículo 95 y 96), el segundo trata del Consejo de Justicia en Cataluña (artículos 97 a 100) y el tercero, el más extenso, comprende las competencias de la Generalitat sobre Administración de Justicia (artículos 101 a 109).
} 


\section{Regulación Estatutaria.}

Centrándonos el Estatuto Catalán, aprobado por Ley Orgánica 6/2006, de 19 de julio, de reforma del Estatuto de Autonomía de Cataluña, en su redacción originaria establecía en su artículo 97 que "el Consejo de Justicia de Cataluña es el órgano de gobierno del poder judicial en Cataluña. Actúa como órgano desconcentrado del Consejo General del Poder Judicial, sin perjuicio de las competencias de este último, de acuerdo con lo previsto en la Ley Orgánica del Poder Judicial."

Por tanto nos encontramos ante un órgano que tiene por finalidad desempeñar el gobierno del Poder Judicial en el territorio de Cataluña, afirmándose que actuará como órgano desconcentrado del Consejo General del Poder Judicial, sin perjuicio de las competencias de éste y conforme a lo dispuesto en la Ley Orgánica del Poder Judicial.

Sin embargo el Estatuto andaluz, en su artículo 144.1, lo define como el órgano de gobierno de la Administración de Justicia en Andalucía, de acuerdo con lo previsto en la Ley Orgánica del Poder Judicial.

Lo primero que llama la atención es que los redactores del Estatuto andaluz definen, en principio, al Consejo de Justicia, de manera diferente a como lo hace el Estatuto de Cataluña, al configurarlo como el órgano de gobierno de la Administración de Justicia en Andalucía, lo que podría entenderse conforme a la doctrina del Tribunal Constitucional ${ }^{16}$, que dicho precepto se refiere al "Gobierno de la Administración de la Administración de Justicia", o sea a los medios personales y materiales puestos a disposición del Poder Judicial para poder ejercer su función. Sin embargo la naturaleza de un órgano no le viene dada por la denominación que el legislador le dé, si no por las atribuciones concretas que le otorgue la ley. Por tanto habremos de esperar a la exposición de dichas atribuciones para determinar si ambos Consejos gozan de la misma naturaleza.

En cuanto a la composición de dichos Consejos, ambos Estatutos de Autonomía (artículo 99.1 del EAC y 144.2 del EAA), señalan que estarán constituidos por el Presidente o Presidenta del Tribunal Superior de Justicia que lo presidirá y por los miembros que se nombre, de acuerdo con lo previsto en la Ley

${ }^{16}$ Vid. STC 56/1990, de 29 de marzo (BOE de 4 de mayo), Ponente: Díaz Eimil, E., FJ 6 o. 
Orgánica del Poder Judicial, entre Jueces, Magistrados o juristas de reconocido prestigio, correspondiendo a los Parlamentos autonómicos la designación de los miembros que determine dicha Ley.

Por lo que respecta a las atribuciones de estos Consejos de Justicia, uno y otro Estatuto de Autonomía las regulan en similares términos (artículo 99.2 del EAC y 144.4 del EAA), de tal manera que DEL RÍO MUÑOZ ${ }^{17}$ las clasifica en los siguientes grupos:

a) Nombramiento: participar en la designación de la Presidencia del Tribunal, Presidentes de Sala y Presidentes de las Audiencias Provinciales, así como proponer los nombramientos y ceses de jueces y Magistrados incorporados temporalmente en funciones de apoyo o sustitución y la adscripción de los mismos a los órganos que requieran refuerzo.

b) Personal: Instruir expedientes y ejercer funciones disciplinarias.

c) Gobierno: participar en la planificación de la inspección de juzgados y tribunales, ordenar estas y realizar propuestas en este ámbito, así como atender las órdenes de inspección que inste el Gobierno.

d) Asesoramiento: informar los recursos de alzada interpuestos contra los acuerdos de los órganos de gobierno de los tribunales y juzgados e informar de las propuestas de revisión, delimitación y modificación de las demarcaciones territoriales y las propuestas de creación de Secciones y Juzgados.

Asimismo se incluye en ambos supuestos la presentación de una memoria anual a los Parlamentos autonómicos correspondientes sobre el estado y funcionamiento de la Administración de Justicia y las demás funciones que les atribuyan la LOPJ u otras leyes, así como las que les delegue el Consejo General del Poder Judicial.

A su vez podemos distinguir con COLOMER HERNÁNDEZ ${ }^{18}$ entre competencias complementarias de las que son de titularidad del CGPJ (las relacionadas en la clasificación anterior en las letras a), c), d) y la presentación de

${ }^{17}$ DEL RÍO MUÑOZ, F. "El Poder Judicial y reformas estatutaria..." Op. Cit., p. 14-15.

${ }^{18}$ COLOMER HERNÁNDEZ, I. "El Consejo de Justicia de Andalucía." En MANUEL JOSÉ TEROL BECERRA et alii, Comentarios al Estatuto..., Op. Cit., pp. 477-478. 
una memoria anual) y de otra parte, las competencias que sustituyen a las del CGPJ (las relacionadas en la letra b) y las que les delegue el Consejo General del Poder Judicial).

Luego vistas las competencias que ambos Estatutos de Autonomía otorgan a sus Consejos de Justicia, entendemos que los dos Consejos gozan de la misma naturaleza jurídica, independientemente de que el Estatuto Catalán lo defina como el "órgano de gobierno del Poder Judicial en Cataluña" y que el andaluz se refiera a él como el "órgano de gobierno de la Administración de Justicia en Andalucía", ya que el legislador autonómico no se esta refiriendo a la "Administración de la Administración de Justicia" sino al Poder Judicial, o sea a la Administración de Justicia en sentido estricto.

\section{Naturaleza jurídica de los Consejos de Justicia.}

A la vista de la regulación estatutaria expuesta cabe preguntarse cual es la naturaleza jurídicas de los Consejos de Justicia autonómicos, o sea si nos encontramos ante órganos descentralizados o ante órganos desconcentrados, si nos encontramos ante órganos estatales o autonómicos.

En esta materia la doctrina está dividida, planteándose COLOMER HERNÁNDEZ ${ }^{19}$ la cuestión de que es difícil fijar la naturaleza jurídica de los Consejos de Justicia, ya que la regulación estatutaria de los mismos no permite formarse una idea adecuada sobre ello. Sin embargo, para que puedan existir como tales integrados en el Gobierno del Poder Judicial deben estar regulados o previstos en la LOPJ y de esta manera se convertirían en órganos esenciales para la gestión y el gobierno de la Administración de Justicia en los términos que la LOPJ les pueda atribuir si es que llega a hacerlo.

Por tanto, podría pensarse que estos Consejos de justicia se configuran como una desconcentración administrativa de un órgano estatal en el ámbito autonómico, siendo por consiguiente órganos desconcentrados del Consejo General del Poder Judicial.

Otros como GONZÁLEZ PÉREZ ${ }^{20}$ los consideran como una manifesta-

\footnotetext{
${ }^{19}$ En el mismo sentido COLOMER HERNÁNDEZ, I. "El Consejo de Justicia ...”, Op. Cit., pp. 472-473.

${ }^{20}$ GONZÁLEZ PÉREZ, J., "Los atentados al modelo de justicia de la Constitución de 1978” en $R e$ vista Española de Derecho Administrativo (REDA), Núm. 134, abril/junio 2007.

http://www.aranzadi.es/index.php/informacion-juridica/doctrina/constitucional-comunitario/losatentados-al-modelo-de-justicia-de-la-constitucion-de-1978 [última vista 1 de octubre de 2012].
} 
ción de autonomía política en el ámbito de la Administración de Justicia, conceptuándolos como órganos autonómicos propios de las Comunidades Autónomas y no como órganos desconcentrados del CGPJ.

Por nuestra parte, vista la regulación que se les ha dado por el Estatuto de Autonomía de Andalucía y por el Estatuto de Autonomía de Cataluña en su original redacción, nos inclinamos por considerarlos como órganos descentralizados y no simplemente desconcentrados del CGPJ, coincidiendo en que se trata de órganos autonómicos y no estatales, pues qué duda cabe que los Estatutos de Autonomía lo que pretenden con los Consejos de Justicia es descentralizar el Poder Judicial al definirlos como órganos de Gobierno del Poder Judicial o de la Administración de Justicia [Administración de Justicia en sentido estricto] en la Comunidad Autónoma.

Así, si bien es cierto que algunas de sus atribuciones son respetuosas con el bloque de constitucionalidad como las contenidas en los apartados f), g), h), i) del artículo 98.2 del Estatuto de Autonomía para Cataluña y las relacionadas en los apartados f), g), h), i) del artículo 144.4 del Estatuto de Autonomía para Andalucía (o sea las que consisten en precisar y aplicar, cuando proceda, en el ámbito de la Comunidad Autónoma, los reglamentos del Consejo General del Poder Judicial. Informar sobre las propuestas de revisión, delimitación y modificación de las demarcaciones territoriales de los órganos jurisdiccionales y sobre las propuestas de creación de secciones y juzgados. Presentar una memoria anual al Parlamento sobre el estado y el funcionamiento de la Administración de Justicia en la Comunidad Autónoma. Todas las funciones que le atribuyan la Ley Orgánica del Poder Judicial y las Leyes del Parlamento, y las que le delegue el Consejo General del Poder Judicial).

No es menos cierto que se les otorgan otras competencias que son típicas de un órgano de gobierno del Poder Judicial como son las contenidas en los apartados a), b), c) d) y e) del artículo 98.2 del EAC y las relacionadas en los apartados a), b), c) d) y e) del artículo 144.4 del EAA (o sea las que consisten en la participación en la designación de presidentes de órganos judiciales, la expedición de nombramientos y ceses de Jueces y Magistrados temporales, funciones disciplinarias sobre Jueces y Magistrados ${ }^{21}$, inspección de Tribunales y infor-

${ }^{21}$ Sobre esta materia COLOMER HERnÁNDEZ, I. "El Consejo de Justicia ...”, Op. Cit., p. 478, señala que "la competencia para el ejercicio de las funciones disciplinarias constituye una atribución exorbitante a favor del Consejo de Justicia que contradice frontalmente lo dispuesto en el artículo 421 LOPJ que al determinar el órgano competente para la imposición de las diversas sanciones disciplinarias no tiene en consideración a los órganos autonómicos. Por otra parte, la atribución que realiza el Estatuto de An- 
mación sobre recursos de alzada contra acuerdos de los órganos de gobierno de los Tribunales y Juzgados de la Comunidad Autónoma), ya que estas atribuciones afectan, sin duda, a la función jurisdiccional propiamente dicha y a la ordenación de los elementos consustanciales a la determinación de la garantía de la independencia en su ejercicio.

\section{El Gobierno del Poder Judicial en la Constitución.}

A quien solo leyera la constitución le sorprendería la regulación del gobierno del Poder Judicial realizada por los Estatutos de nueva generación y materializada a través de los Consejos de Justicia Autonómicos, ya que si analizamos el Título VI de nuestra Norma Suprema, aunque no mencione expresamente que el Poder Judicial es un Poder único y unitario para todo el Estado, podemos concluir que si lo configura de esa manera.

En primer lugar, hemos de partir del artículo 117.5 de la Constitución que señala que el principio de unidad jurisdiccional es la base de la organización y funcionamiento de los Tribunales, que por tanto el Poder Judicial es único y a él le corresponde juzgar y ejecutar lo juzgado. Además el Gobierno de ese Poder Judicial también es único y corresponde al Consejo General del Poder Judicial (artículo 122.2 de la CE).

En segundo lugar, respecto del Tribunal Supremo, es suficientemente claro y contundente el artículo 123.1 al definirlo como órgano jurisdiccional superior en todos los órdenes jurisdiccionales, salvo lo dispuesto en materia de garantías constitucionales.

Y en tercer lugar, existe en nuestro ordenamiento una remisión al legislador orgánico, a través de la Ley Orgánica del Poder Judicial, en todo lo que se refiera a la constitución, funcionamiento y gobierno de los Juzgados y Tribunales, así como el estatuto jurídico de los Jueces y Magistrados de carrera, siendo el Consejo General del Poder Judicial es el órgano de gobierno del mismo (artículo $122 \mathrm{CE}$ ).

Tampoco, podemos dejar pasar por alto, que la propia noción de los Tribunales Superiores de Justicia avala la concepción constitucional de que el Po-

dalucía de competencia para sancionar disciplinariamente a jueces y magistrados a favor del Consejo de Justicia andaluz puede llegar a implicar una lesión de la independencia judicial en el ejercicio de la función jurisdiccional al posibilitar que el personal jurisdicente pueda verse sometido a sanciones disciplinarias impuestas por un órgano no legitimado conforme a la previsión de la LOPJ." 
der Judicial es único para todo el Estado, ya que el propio artículo 152.1 CE señala que un Tribunal Superior de Justicia culminará la organización judicial en el ámbito territorial de la Comunidad Autónoma sin perjuicio de la jurisdicción que corresponde al Tribunal Supremo. Con ello, podemos concluir que los Tribunales Superiores de Justicia están dentro de las Comunidades Autónomas pero no son órganos de éstas ${ }^{22}$.

Además, lo afirmado no constituye ninguna anomalía dentro de los Estados compuestos. Así en cuanto a los Estados Regionales de nuestro entorno podemos observar que todos ellos conceptúan la organización del Poder Judicial como unitaria. Tal es el caso de Italia ${ }^{23}$ o Reino Unido $^{24}$, donde no existen Tribunales regionales, dependientes de las regiones, sino que su organización judicial culmina en un Tribunal Supremo o de Casación.

Respecto de los Estados Federales, éstos tienden, como señala VIRGALA FORURIA ${ }^{25}$, "a la uniformización de sus entes territoriales y les repelen las diferencias excesivas entre ellos, pues su objetivo no es otro que la construcción de una nación común y no la desmembración de una existente, mientras que en España los máximos promotores de la introducción del federalismo son los paladines de la diferencia y de las soluciones confederales en los que la parte y el todo se relacionan de igual a igual."

No obstante, si nos fijamos en la organización del Poder Judicial en estos Estados, puede observarse que no siguen un patrón uniforme ${ }^{26}$. En este sentido

${ }^{22}$ En el mismo sentido GUZMÁN FLUJA, V. "El Tribunal Superior de Justicia de Andalucía.” En MANUEL JOSÉ TEROL BECERRA et alii, Comentarios al Estatuto de Autonomía para Andalucía, Tirant lo Blanch, Valencia, 2009, p. 443.

${ }^{23}$ Sobre el sistema judicial de Italia, resulta interesante la lectura de SAIZ GARITAONANDIA, A., "Otras formas de gobierno en Estados compuesto. Los casos de Italia y los Estados Unidos de América." Revista Vasca de Administración Pública, Núm. 83, 2009, pp. 165-166.

${ }^{24}$ Sobre el Derecho Orgánico Judicial es relevante la lectura de AGIRREAZKUENAGA, I., "Modelos comparados de organización judicial y régimen de selección o elección de jueces y magistrados" $R e^{-}$ vista Poder Fudicial, $\mathrm{N}^{\circ}$ 75, 2004, pp. 10-56, donde analiza y compara el autor los sistemas anglosajón (Inglaterra, Australia, Canadá y Estados Unidos) y continental (Alemania, Holanda, Noruega y Finlandia, Francia, Italia, Portugal) y el caso especial e inclasificable de Suiza. Sobre el sistema judicial y la organización judicial en el Reino Unido resulta interesante la visita de https://e-justice.europa.eu/content_ordinary_courts-18-uk-es.do?member=1 [última visita 20 de agosto de 2012].

${ }^{25}$ VIRGALA FORURIA, E. "El Poder Judicial en las Comunidades Autónomas" Estudios de Derecho fudicial. Vol. 90, 2006, p. 406.

${ }^{26}$ En el mismo sentido puede leerse CÁMARA VILLAR, G., et alii, Por una reforma Federal del Estado Autonómico, Fundación Alfonso Perales, 2012, p. 48, donde señala el autor que "sin embargo, la estructu- 
puede decirse que el modelo de poder judicial de Estados Unidos ${ }^{27}$ es la excepción al prever la existencia de dos poderes judiciales, el federal y el federado. Pero no podemos dejar pasar por alto que también existen Estados Federales donde el sistema de organización judicial es unitario. Estos Estados son Bélgica $^{28}$, con Tribunales de primera instancia, apelación y casación, o Austria ${ }^{29}$, con Tribunales de Distrito, de primera instancia, apelación y casación.

ración del poder judicial en los Estados federales no sigue un patrón uniforme. La primera posibilidad, y la más habitual en los Estados federales, como Estados Unidos, Canadá y otros países latinoamericanos, como México, consiste efectivamente en prever la existencia de dos poderes judiciales: el federal, llamado a conocer de las causas fundadas en derecho federal, y el federado, responsable del conocimiento de las controversias que dirimen la aplicación del derecho federado. Existen, con todo, Estados federales con un poder judicial unitario, como Austria y Bélgica, donde el poder judicial de la unidad federada conoce de todas las controversias, estén fundadas en derecho federal o en derecho periférico. En otros casos, la primera instancia es servida por tribunales territoriales, con independencia del origen del derecho aplicable, mientras que las instancias superiores corresponden a tribunales de la federación, como ocurre en Alemania, Suiza y Australia."

Sobre la organización del Poder Judicial en los modelos federales señala BALLARÍN IRIBARREN, J., "Poder judicial y estado compuesto: el caso de los Estados Unidos" en MARIANO BAENA DEL ALCÁZAR, et alii, Actualidad y perspectiva del derecho público a fines del siglo XX: homenaje al profesor Garrido Falla, Universidad Complutense, Madrid, 1992, p. 2025, que "la organización del Poder Judicial sigue distintos modelos en los sistemas federales; básicamente puede hablarse de sistemas «duales» y de sistemas «integrados». El modelo «dual» es el propio de los ordenamientos federales americanos (con la excepción del Canadá). En este modelo, existe una estructura judicial federal paralela a la de la Estados miembros, o, en otras palabras, órganos judiciales federales no sólo en la cúspide de la organización jurisdiccional, sino también en sus niveles inferiores o intermedios Así, en los Estados Unidos existen, además de la Corte Suprema, otros tribunales federales: las district courts, las courts of appeals y varios tribunales federales especializados. En los sistemas «integrados» existen tan sólo órganos judiciales federales superiores, de suerte que, en principio, la aplicación del derecho federal corresponde, en primera instancia, a los órganos judiciales de los Estados miembros. Sentada esta característica común pueden distinguirse dos variantes: a) La integración entre el sistema judicial federal y el estatal (de los Estados miembros) es total cuando los órganos del último se ven sujetos al control del tribunal (o tribunales) federales tanto si aplican derecho federal como si aplican derecho estatal. Este es el caso de los ordenamientos federales de Canadá y Australia. b) La integración es parcial cuando los tribunales estatales se ven sujetos al control de los federales sólo cuando aplican derecho federal. Este es el caso de la República Federal de Alemania y de Suiza. Por último debe hacerse mención de otra posibilidad la organización exclusivamente federal del poder judicial. El artículo 82.1 de la Constitución austriaca establece: «Toda jurisdicción emana de la Federación»."

27 Sobre el sistema judicial de Estados Unidos, puede leerse SAIZ GARITAONANDIA, A., "Otras formas de gobierno en Estados compuesto...", Op. Cit., pp. 180-181.

${ }^{28}$ Sobre la organización de los tribunales y los juzgados en Bélgica puede consultarse https://e-justice.europa.eu/content_judicial_systems_in_member_states-16-be-es.do [última visita 27 de agosto de 2012]. Igualmente puede verse http://ec.europa.eu/civiljustice/org_justice/org_justice_bel_es.htm[última visita 27 de agosto de 2012].

${ }^{29}$ Para tener una visión de conjunto de los órganos jurisdiccionales de Austria véase https://e-justice.europa.eu/content_judicial_systems_in_member_states-16-at-es.do?member=1 [Última visita 27 de agosto de 2012]. 


\section{Posición del Tribunal Constitucional sobre el Consejo de Jus- ticia de Cataluña.}

Contra la regulación del Consejo de Justicia de Cataluña, así como contra la práctica totalidad del Estatuto, se interpuso recurso de inconstitucionalidad, habiendo dictado el Alto Tribunal la sentencia $31 / 2010^{30}$. Y siguiendo su contenido, en lo relativo al artículo 97 del EAC (que define al Consejo de Justicia de Cataluña como el órgano de gobierno del poder judicial en Cataluña que además actúa como órgano desconcentrado del Consejo General del Poder Judicial, sin perjuicio de las competencias de este último, de acuerdo con lo previsto en la Ley Orgánica del Poder Judicial) y concretamente el FJ 47, podemos afirmar que dada la configuración constitucional del Poder Judicial, es notorio que el Estatuto Catalán incurre en un evidente exceso al crear el Consejo de Justicia de Cataluña al que califica de "órgano de gobierno del Poder Judicial en Cataluña" y cuyos actos los serían de un "órgano desconcentrado del Consejo General del Poder Judicial", añadiendo que "el Poder Judicial no puede tener más que un órgano de gobierno, cuyo estatuto y funciones quedan expresamente reservados al legislador orgánico." Por tanto el Estatuto vulnera lo dispuesto en los artículos 122.2 y 149.1.5 de la C.E., "pues ningún órgano, salvo el Consejo General del Poder Judicial, puede ejercer la función de gobierno de los órganos jurisdiccionales integrados en el Poder Judicial, exclusivo del Esta-

${ }^{30}$ STC 31/2010, de 28 de junio (BOE de 16 de julio). Ponente: Rodríguez-Zapata Pérez, J. De la lectura de la sentencia parece inferirse que lo único que pretende el Tribunal Constitucional es salvaguardar al legislador y ello se observa con claridad en la gran cantidad de aspectos ambiguos o abiertos que deja y en su pobre argumentación jurídica, seguramente derivada por el elevado número de artículos impugnados y por el difícil acuerdo o consenso logrado entre los magistrados para sacarla adelante. Todo ello puede llevarnos a una gran conflictividad en el futuro, pues hay muchos preceptos que el Alto Tribunal reescribe lo que supone, en palabras de DELGADO BARRIO (Voto particular formulado el Magistrado don Javier Delgado Barrio respecto de la Sentencia de 28 de junio de 2010, dictada en el recurso de inconstitucionalidad núm. 8045-2006. Apartado 3.) que "en esta sentencia el Tribunal ha operado no como lo que es - un órgano jurisdiccional- sino como lo que no es - un órgano legislativo-, pues crea un Estatuto nuevo", llevando este tipo de interpretación a un vaciamiento del contenido normativo del Estatuto y con remisiones en otras ocasiones a Leyes estatales como ocurre en la regulación del Consejo de Justicia.

En Cataluña la sentencia cayó como un cántaro de agua fría, pues no contentó a las fuerzas políticas catalanas que han visto malogradas sus aspiraciones de mayor autogobierno y de un reconocimiento más profundo de la singularidad del pueblo catalán. Tampoco ha contentado a la doctrina jurídica catalana, así puede verse APARICIO PÉREZ, M. A. "Comentarios a la Sentencia 31/2010. Sobre el Poder Judicial." Revista Catalana de dret públic, Núm. Especial Sentencia 31/2010 del Tribunal Constitucional, sobre el Estatuto de Autonomía de Cataluña 2006, pp. 199-205. también puede leerse CABELLOS ESPIÉRREZ, M. A. "Poder Judicial y modelo de Estado en la Sentencia sobre el Estatuto de Autonomía de Cataluña." Revista Catalana de dret públic, Núm. Especial Sentencia 31/2010 del Tribunal Constitucional, sobre el Estatuto de Autonomía de Cataluña 2006, pp. 206-211. 
do, ni otra ley que no sea la Orgánica del Poder Judicial puede determinar la estructura y funciones de aquel Consejo dando cabida, en lo que ahora interesa, y en su caso, a eventuales fórmulas de desconcentración que, no siendo constitucionalmente imprescindibles, han de quedar, en su existencia y configuración, a la libertad de decisión del legislador orgánico con los límites constitucionales antes expresados."

Ahora bien, siguiendo lo expuesto en el citado fundamento jurídico, que dicho precepto sea inconstitucional y nulo "no significa fatalmente la inconstitucionalidad misma del órgano en cuestión, pues sólo si todas y cada una de sus concretas atribuciones se correspondieran, además, con esa cualificación impropia, sería inevitable la inconstitucionalidad y nulidad de un órgano cuya existencia únicamente tendría razón de ser para el ejercicio de unos cometidos constitucionalmente inaceptables ${ }^{31}$. El art. 97 EAC es, por tanto, inconstitucional en la medida en que califica al Consejo de Justicia de Cataluña como "órgano de gobierno del poder judicial" que "actúa como órgano desconcentrado del Consejo General del Poder Judicial". La pervivencia del Consejo de Justicia de Cataluña, una vez excluida su inconstitucional conceptuación, dependerá del juicio que merezcan las atribuciones que se le confieren en el art. 98 EAC.

En todo caso, la inconstitucionalidad de principio advertida ya en el art. 97 EAC ha de implicar, por conexión o consecuencia, la de los arts. 98.3 y 100.1 EAC, no impugnados, en cuanto el primero parte de la posibilidad de que el Consejo de Justicia dicte resoluciones en materia de nombramientos, autorizaciones, licencias y permisos de Jueces y Magistrados y toda vez que la recurribilidad en alzada de determinados actos del Consejo de Justicia de Cataluña ante el Consejo General del Poder Judicial resulta lógicamente de la definición de aquél como órgano desconcentrado de este último.

Por tanto, el art. 97 EAC, así como el apartado 3 del art. 98 EAC y el apartado 1 del art. $100 \mathrm{EAC}$, son inconstitucionales y nulos (Vid. FJ 47).

Luego el Tribunal constitucional no afirma que no puedan existir en las Comunidades Autónomas Consejos de Justicia, si no que lo que señala es que di-

${ }^{31}$ Una crítica muy acertada a este párrafo de la sentencia la encontramos en APARICIO PÉREZ, M. A. "Comentarios a la Sentencia 31/2010...", Op. Cit., p. 205, donde señala que "o sea, un órgano inexistente ( ¿"rampante"?) es además amputado en su composición y finalmente diezmado en sus atribuciones. Tal vez haya existido un exceso de influencia literaria en la redacción de estos extremos de la Sentencia." 
chos Consejos no pueden ser órganos de Gobierno del Poder Judicial y por tanto no se pueden arrogar competencias que invadan las del Consejo General del Poder Judicial en esta materia, sin perjuicio de las competencias que en el futuro pudiera otorgarles la Ley Orgánica del Poder Judicial si finalmente llega a regularlos ${ }^{32}$.

Así, el Tribunal Constitucional declara la inconstitucionalidad de varios apartados del artículo 98 relativos a las atribuciones del Consejo de Justicia de Cataluña, concretamente los apartados 2. a), b), c), d), e) y apartado 3(o sea las que consisten en la participación en la designación de presidentes de órganos judiciales, la expedición de nombramientos y ceses de Jueces y Magistrados temporales, funciones disciplinarias sobre Jueces y Magistrados, inspección de Tribunales e información sobre recursos de alzada contra acuerdos de los órganos de gobierno de los Tribunales y Juzgados de la Comunidad Autónoma).

También declara la inconstitucionalidad del artículo 95.5 y 6, y, por las mismas razones (Vid. FJ 48), en lo que refiere a la frase "y con la Participación del Consejo de Justicia de Cataluña" por dar participación a éste en el nombramiento del Presidente o Presidenta del Tribunal Superior de Justicia de Cataluña.

Igualmente, declara (Vid. FJ 49) que incurre en exceso el Estatuto de Autonomía catalán, cuando en el artículo 99.1, a propósito de fijar la composición del Consejo de Justicia, establece que estará presidido por el Presidente o Presidenta del Tribunal Superior de Justicia, declarando dicho inciso inconstitucional, ya que el Consejo de Justicia de ninguna manera puede arrogarse funciones de gobierno de los jueces.

Las únicas atribuciones que declara el Tribunal Constitucional que puede arrogarse el Consejo de Justicia de Cataluña son las siguientes:

"Artículo 98. Atribuciones

1. Las atribuciones del Consejo de Justicia de Cataluña son las que establecen el presente Estatuto, la Ley Orgánica del Poder Judicial, las leyes que apruebe el Parlamento y las que, si procede, le delegue el Consejo General del Poder Judicial.

\footnotetext{
${ }^{32}$ Sobre la territorialización del Poder Judicial, Vid. BERLANGA RIBELLES, E. "El Gobierno del Poder Judicial. Consejo General y Consejos Territoriales", Estudios de derecho judicial, Núm. 90, 2006, pp. 339-346. Igualmente es ilustrativo el artículo de CÁMARA VILLAR, G, "La descentralización del Gobierno del Poder Judicial y el proyecto de reforma de la LOPJ", Estudios de derecho judicial, Núm. 90, 2006, pp. 313-338.
} 
2. Las atribuciones del Consejo de Justicia de Cataluña respecto a los órganos jurisdiccionales situados en el territorio de Cataluña son, conforme a lo previsto en la Ley Orgánica del Poder Judicial, las siguientes:

f) Precisar y aplicar, cuando proceda, en el ámbito de Cataluña, los reglamentos del Consejo General del Poder Judicial.

g) Informar sobre las propuestas de revisión, delimitación y modificación de las demarcaciones territoriales de los órganos jurisdiccionales y sobre las propuestas de creación de secciones y juzgados.

h) Presentar una memoria anual al Parlamento sobre el estado y el funcionamiento de la Administración de Justicia en Cataluña.

i) Todas las funciones que le atribuyan la Ley Orgánica del Poder Judicial y las leyes del Parlamento, y las que le delegue el Consejo General del Poder Judicial.

4. El Consejo de Justicia de Cataluña, a través de su presidente o presidenta, debe comunicar al Consejo General del Poder Judicial las resoluciones que dicte y las iniciativas que emprenda y debe facilitar la información que le sea pedida" 33 .

Como podemos observar, las funciones que restan a favor del Consejo de Justicia de Cataluña, respecto a los Órganos Jurisdiccionales situados en su territorio, conforme a lo previsto en la Ley Orgánica del Poder Judicial, son las relativas a cualquier materia que no afecte a los órganos jurisdiccionales, en sentido estricto, y que tampoco afecten al estatuto jurídico de los Jueces y Magistrados, o sea que no invadan la Administración de Justicia en sentido estricto.

En cuanto a la composición del Consejo de Justicia (artículo 99 del EAC), después de la citada sentencia, queda fuera del mismo el Presidente o Presidenta del Tribunal Superior de Justicia, a quien en su redacción originaria se le atribuía la presidencia de dicho Consejo, a resultas de lo que diga el legislador orgánico.

\section{El caso andaluz.}

Analizada la posición del Tribunal Constitucional respecto del Consejo de Justicia de Cataluña, cabe preguntarse como afecta el contenido de la STC

33 A sensu contrario CABELLOS ESPIÉRREZ, M. A. "Poder Judicial y modelo de Estado en la Sentencia sobre el Estatuto...", Op. Cit., pp. 209-210, donde critica en este aspecto la sentencia, pues para él la poda de atribuciones hecha al Consejo de Justicia es injustificada, toda vez que el EAC no regula el Consejo de Justicia de Cataluña como un órgano de gobierno del Poder Judicial autonómico sino como un órgano desconcentrado del CGPJ. 
31/2010 a la regulación estatutaria andaluza a pesar de no haber sido recurrida de inconstitucionalidad, dado que como antes hemos dicho el Estatuto andaluz va de la mano del catalán habiéndose dado a muchos de sus preceptos idéntica o similar redacción.

Así el Estatuto de Andalucía, aprobado por Ley Orgánica 2/2007, de 19 de marzo, que dedica el Título V a "El Poder Judicial en Andalucía", debiéndonos centrar nuestro estudio en lo que aquí interesa, en su Capítulo II que lleva por rúbrica "El Consejo de Justicia de Andalucía"34. De tal manera que el artículo 144.1 del Estatuto, lo define como el órgano de gobierno de la Administración de Justicia en Andalucía, de acuerdo con lo previsto en la Ley Orgánica del Poder Judicial, que está integrado, entre otros, artículo 144.2, por el Presidente o Presidenta del Tribunal Superior de Justicia que lo presidirá, fijándose sus atribuciones en el apartado $4^{\circ}$ del artículo 144 en idénticos términos a como lo hace el Estatuto de Autonomía catalán en su artículo 98.

Sin mayor esfuerzo, podemos afirmar, de la lectura de la sentencia de 28 de junio de 2010 del Tribunal Constitucional, que el artículo 144.1 incurre en exceso al crear el Consejo de Justicia en Andalucía al que califica de "órgano de gobierno de la Administración de Justicia en Andalucía, de acuerdo con lo previsto en la Ley Orgánica del Poder Judicial”, ya que el Poder Judicial no puede tener más que un órgano de gobierno, cuyo estatuto y funciones quedan expresamente reservados al legislador orgánico ${ }^{35}$.

Sin embargo, al igual que hemos afirmado para Cataluña, que dicho precepto pueda ser inconstitucional no significa la inconstitucionalidad misma del órgano en cuestión, ello dependerá de que las concretas atribuciones otorgadas se correspondieran además con esa calificación impropia, ya que la existencia del órgano únicamente tendría razón de ser para el ejercicio de unos cometi-

\footnotetext{
${ }^{34}$ Sobre esta cuestión Vid. CRUZ VILLALÓN, P. y MEDINA GUERRERO, M., et alii, Comentarios al Estatuto de Autonomía para Andalucía, Centro de Publicaciones no Oficiales. Parlamento de Andalucía, Sevilla, 2012. TEROL BECERRA, M., et alii, Comentarios al Estatuto de autonomía para Andalucía, Tirant lo Blanch, Valencia, 2009. Así como AGUDO ZAMORA, M., et alii, El Estatuto de Autonomía de Andalucía de 2007, Fundación Pública Andaluza Gentro de Estudios Andaluces, 2008. Igualmente BALAGUER CALLEJÓN, F., et alii, El nuevo Estatuto de Andalucía, Tecnos, 2007.

${ }^{35} \mathrm{Si}$ es respetuoso con el bloque de constitucionalidad el Estatuto de Autonomía de Aragón, ya que en éste existe una remisión sin condiciones a lo que disponga el legislador orgánico, estableciendo el artículo 64.2 que "el Consejo de Justicia de Aragón tendrá la consideración, naturaleza, competencias y facultades que le atribuya la Ley Orgánica del Poder Judicial. Asimismo, participará en todos los procesos de designación que le atribuya dicha Ley."
} 
dos constitucionalmente aceptables y siempre y cuando no invadan la Administración de Justicia en sentido estricto.

Lo que ocurre, en el presente caso, es que las atribuciones que se le confieren el apartado 4, del artículo 144, con las letras a), b), c), d) y e) son sustancialmente iguales, en su redacción, a las que han sido declaradas inconstitucionales por el Tribunal Constitucional, por lo que estas atribuciones deberían correr igual suerte que las del Estatuto Catalán.

De la misma manera e idéntico razonamiento, podrían ser declarados inconstitucionales los apartados 2 y 5 del artículo 144 ya que así lo ha puesto de manifiesto el Tribunal Constitucional a propósito del Estatuto Catalán, afirmando el Alto Tribunal que son contrarios a la Constitución y nulos, en la medida en que el Consejo de Justicia no puede ser órgano de Gobierno del Poder Judicial y por tanto no se puede arrogar competencias que invadan las del Consejo General del Poder Judicial en esta materia que afecten a los Órganos Jurisdiccionales, en sentido estricto, o que afecten al estatuto jurídico de los Jueces y Magistrados.

Sin embargo el Estatuto Andaluz no ha sido recurrido de inconstitucionalidad por lo que a nuestro entender, en aras de la seguridad jurídica, la consecuencia de la STC 31/2010, es que no sería correcto ni deseable que la Comunidad Autónoma Andaluza aplicase los preceptos idénticos o semejantes a los del Estatuto de Autonomía catalán, que han sido declarados inconstitucionales por el Alto Tribunal, o que aquellos que han sido reinterpretados los aplicase de forma diferente a como ha dicho el Tribunal Constitucional que se deben de interpretar, ya que si así lo hiciera cualquier legitimado podría acudir a los Tribunales ordinarios de justicia recurriendo la correspondiente aplicación y pedir que se plantee una cuestión de inconstitucionalidad, cuestión que, por otra parte, de no reformarse el ordenamiento jurídico vigente, debería ser estimada sin mayores esfuerzos por nuestro Alto Tribunal.

Ahora bien, cabe preguntarse que ocurre con los otros Consejos de Justicias creados por las otras Comunidades Autónomas. Así respecto de Valencia, Baleares y Aragón, sus Estatutos los crean, pero no los definen como órganos de gobierno del Poder Judicial. Es más cuanto a su estructura, composición y funciones se remiten a lo que dispongan futuras leyes, autonómicas y estatales, de acuerdo con lo que prevea la Ley Orgánica del Poder Judicial y dentro del ámbito de las competencias en esta materia de cada Comunidad Autónoma. En cuanto a Castilla y León ha de decirse otro tanto, si bien su Estatuto prevé su creación pero no llega a crearlo. Y por último Extremadura lo crea igualmen- 
te pero no como un órgano del Poder Judicial en su territorio, sino como un órgano de participación institucional en el Gobierno y Administración de Justicia de la Comunidad Autónoma y conforme a lo que disponga la Ley Orgánica del Poder Judicial.

Por tanto, a nuestro juicio, para el caso de que el legislador orgánico decida crear los Consejos de Justicia autonómicos, en los términos señalados por el Tribunal Constitucional, los Estatutos de Autonomía de Valencia, Baleares, Aragón, Castilla y León y Extremadura son congruentes con lo dispuesto en los artículos 122.2 y $149.15 \mathrm{CE}$ y acordes con el bloque de constitucionalidad, pues no los definen como órganos de Gobierno del Poder Judicial en la Comunidad Autónoma.

\section{Propuestas.}

Lo primero que hemos de preguntarnos es si es posible la descentralización del Poder Judicial o de su órgano de gobierno. La respuesta ha de ser necesariamente negativa, pues como hemos afirmado anteriormente de la regulación constitucional del Poder Judicial se infiere, sin albergarse duda alguna, que el mismo es único para todo el Estado. Por tanto, encontrándonos ante un órgano que es único no cabe que el mismo sea descentralizado, ya que el propio concepto de descentralización lo impide. Tampoco puede descentralizarse su órgano de gobierno por las misma razón y además por que sería imposible que pudiese controlar a los diferentes órganos de gobierno del Poder Judicial de las Comunidades Autónomas ${ }^{36}$.

La segunda cuestión que habría de plantearse es si es posible la desconcentración administrativa del Poder Judicial, siendo la respuesta afirmativa. Pero esta desconcentración administrativa sólo puede decidirla el legislador orgánico y no a través de cualquier ley orgánica sino que ha de ser a través de la Ley Orgánica del Poder Judicial (art. 122.2 CE) ${ }^{37}$.

Aun aceptando lo anterior, cabe preguntarse si podría ahora el legislador orgánico, a través de la Ley Orgánica del Poder Judicial, crear los Consejos de Justicia Autonómicos en los términos en los que los ha regulado el legislador autonómico en los Estatutos de Autonomía de Cataluña o de Andalucía.

\footnotetext{
${ }^{36}$ En el mismo sentido puede leerse VIRGALA FORURIA, E. "El Poder Judicial...", Op. Cit., p. 402.

${ }^{37}$ En el mismo sentido la STC 31/2010, FJ 47.
} 
Con anterioridad ha quedado suficientemente claro, salvo que se modifique la Constitución, que el Poder Judicial es único para todo el Estado y que no puede tener más que un órgano de gobierno, el CGPJ, y como quiera que esos Estatutos de Autonomía lo que pretendían era una verdadera descentralización del Poder Judicial en vez de una desconcentración, la respuesta a dicha cuestión es negativa de necesidad ${ }^{38}$.

Es más, aun aceptando la posibilidad, de una regulación desconcentrada del Poder Judicial, que es posible desde la perspectiva constitucional, tenemos que preguntarnos si resultaría conveniente la creación de los Consejos de Justicia Autonómicos como órganos desconcentrados del gobierno del Poder Judicial.

A nuestro juicio no resulta conveniente. En primer lugar, por que supondría multiplicar por diecisiete el sistema fallido de elección parlamentaria de los integrantes del Consejo General del Poder Judicial al haber propiciado la politización de dicho órgano de gobierno y es que debemos tener presente la experiencia del sistema de designación parlamentaria de los vocales del CGPJ establecido en la LOPJ de 1985, siendo patente que este sistema ha facilitado que las fuerzas políticas tengan abierta una vía para ejercer cierta influencia en la actuación del órgano de gobierno del Poder Judicial ${ }^{39}$. Desde esta perspectiva, la creación y puesta en funcionamiento, en su caso, de los Consejos de Justicia, facilitaría que las Comunidades Autónomas entrasen en esa dinámica de influencias políticas sobre el Poder Judicial, que hasta ahora sólo se produce en el ámbito estatal.

38 En el mismo sentido, CÁMARA VILLAR, G., "Reformas estatutarias y consejos de justicia autonómicos a la luz de la doctrina del Tribunal Constitucional" Teoría y realidad constitucional, Núm. 27, 2011 (Ejemplar dedicado a: La STC 31/2010 sobre el Estatuto de Cataluña), p. 197-220. Señala el autor en la p. 202 "esta insuprimible estatalidad, conforme al principio de unidad, del gobierno del poder judicial impediría la existencia de órganos autonómicos de gobierno del poder judicial desvinculados o independientes del CGPJ, pero no quedan excluidas ni la delegación ni la desconcentración. Se excluye, pues, el establecimiento de órganos de gobierno del poder judicial de naturaleza propiamente autonómica en analogía con lo ocurrido con otras instituciones constitucionalmente dispuestas en la esfera institucional y funcional de los otros poderes, ejecutivo y legislativo, ya que éstos sí son objeto específico y necesario de la descentralización política en sentido propio para que la autonomía constitucionalmente garantizada sea posible."

${ }^{39}$ Sobre esta cuestión Vid., RUI VERDE, "El Poder judicial en las Constituciones de Portugal y España" Anuario de la Facultad de Derecho, Núm. 21, 2003, p. 617-628, donde señala el autor que "el autogobierno de los jueces portugueses es fuerte e independiente, en cuanto en el caso de los jueces españoles se verifica una completa dependencia del poder político, lo que amenaza la real independencia de las magistraturas." 
En segundo lugar, por la más que probable falta de coordinación que se produciría desconcentrando el gobierno de un Poder, que es único para todo el Estado, en diecisiete Consejos de Justicia e incluso económicamente su existencia no se justifica por el incremento de gasto que supondría.

$\mathrm{Y}$ en tercer lugar, porque de crearse estos Consejos, suponemos que vendrían a sustituir el verdadero autogobierno de la Justicia, que es el desempeñado por los órganos de gobierno interno (Salas de Gobierno de los Tribunales Superiores de Justicia), ya que prácticamente todas las competencias que les otorgan los Estatutos de Autonomía actualmente las ostentan las Salas de Gobierno $^{40}$ y ¿Qué razón puede haber para que se proceda a dicha sustitución?

La respuesta quizás esté en que lo que se pretende es reforzar la influencia de las fuerzas políticas autonómicas en el Poder Judicial dentro de su territorio, pero ello, a nuestro juicio, llevaría a la debilitación de la autonomía e independencia judicial.

Entendemos, que si el legislador orgánico, con respeto a la Constitución y con plena libertad, decidiese crear los Consejos de Justicia Autonómicos, como órganos desconcentrados administrativamente del Gobierno del Poder Judicial y con plena subordinación al Consejo General del Poder Judicial, a la vista de lo expuesto anteriormente, supondría desconcentrar un problema para crear otros diecisiete problemas iguales.

Por tanto, aunque tan solo sea para evitar la multiplicación de un problema, consideramos que la creación de dichos Consejos no es urgente ni menos aún necesaria ${ }^{41}$.

No obstante, si el legislador orgánico decide su creación, señala LUCAS MURILLO DE LA GUEVA ${ }^{42}$ que "gestionar todo el conjunto que resulte de

\footnotetext{
${ }^{40}$ En el mismo sentido, CÁMARA VILLAR, G., "Reformas estatutarias y consejos de justicia autonómicos...", Op. Cit., p. 208.

${ }^{41}$ Es más nos atrevemos a invitar al legislador orgánico para que solucione el problema antes de multiplicarlo. ¿Cómo? Dejando en manos de los Jueces y Magistrados la elección de los doce Vocales del CGPJ de procedencia judicial, donde la base de la elección sea un juez/un voto. No nos encontramos ante el clásico dilema de Politización versus Corporativismo, pues el CGPJ está mejorado con los ocho vocales de procedencia no judicial que tienen una visión de la Justicia diferente y que sin duda enriquecen la Institución.

42 LUCAS MURillo De la CUeva, P. "El Poder Judicial en Andalucía." En SANTiago MUÑOZ MACHADO y MANUEL REBOLLO PUIG et alii, Comentarios al Estatuto de Autonomía para Andalucia, p. 981.
} 
la implantación de este diseño requerirá dosis importantes de trabajo, habilidad y prudencia a pesar de las cuales habrá que contar con complicaciones importantes no sólo en el periodo de establecimiento y desarrollo de los Consejos, sino, también, una vez que se hayan instalado y comiencen a funcionar regularmente."

Siendo así las cosas, cabe preguntarse ¿Por qué se ha llegado a esta situación? Nos estamos refiriendo a la creada por los Estatutos de nueva generación en los que se ha intentado forzar la territorialización el Poder Judicial y su Gobierno desde abajo, o sea desde la modificación de los Estatutos de Autonomía.

A este respecto, es preciso tener que presente que el problema de la adecuación del Poder Judicial al Estado Autonómico, como señala VIRGALA FORURIA $^{43}$ "hay que contemplarlo desde dos puntos de vista complementarios: en primer lugar, la existencia de un modelo constitucional de Poder Judicial y, en segundo lugar, la necesidad permanente de intentar forzar ese modelo para que los poderes políticos de determinadas Comunidades Autónomas puedan influir o condicionar a los órganos judiciales situados en esos territorios."

Desde el segundo punto de vista, se puede afirmar que el interés de la Comunidades Autónomas por el Poder Judicial no es ajeno al progresivo fortalecimiento que éste ha venido experimentando desde la entrada en vigor de la Constitución. Y este robustecimiento del Poder Judicial, puede deberse al proceso natural de desarrollo del Estado de Derecho o bien a la tendencia obsesiva de las fuerzas políticas de judicializar la vida política, lo que sin duda influye en la politización de la justicia, debiendo los Jueces resolver estos pleitos, lo que les coloca en un primer plano de la vida pública, otorgándoles una relevancia que no debieran ostentar en el funcionamiento normal del sistema.

Qué duda cabe y no debe sorprendernos, que quienes gobiernan las Comunidades Autónomas, en estas circunstancias, lo que pretendan y quieran sea adecuar el modelo constitucional de Poder Judicial a la realidad territorial del Estado, autonomizando el Poder Judicial, creando un órgano de gobierno del Poder Judicial propio de cada Comunidad Autónoma.

Las Comunidades Autónomas ya no se conforman con potenciar las funciones jurisdiccionales de sus Tribunales Superiores de Justicia, sino que lo que han pretendido, a través de los Estatutos de segunda generación, es poner más

\footnotetext{
${ }^{43}$ VIRGALA FORURIA, E. “El Poder Judicial...”, Op. Cit., p. 399.
} 
énfasis en los aspectos gubernativos que en los jurisdiccionales, de tal manera que el legislador estatutario ya no habla de Administración de Justicia sino de Poder Judicial.

Solo así puede comprenderse la regulación estatutaria de estos Consejos, debiendo tenerse en cuenta que es, en la propia designación de sus miembros, uno de los lugares, donde se aprecia con mayor claridad ese intento de influir y/o controlar al Consejo de Justicia, o sea al Poder Judicial en el ámbito autonómico, ya que según el artículo 144.2 del Estatuto de Autonomía andaluz este Consejo de Justicia estará integrado "por el Presidente o Presidenta del Tribunal Superior de Justicia de Andalucía, que lo preside, y por los miembros elegidos entre Jueces, Magistrados, Fiscales y juristas de reconocido prestigio que se nombren de acuerdo con lo previsto por la Ley Orgánica del Poder Judicial, correspondiendo al Parlamento de Andalucía la designación de los miembros que determine dicha Ley."

No podemos olvidar que es previsible, al igual que ocurre con la designación parlamentaria de los Vocales del CGPJ, que la designación de estos nuevos miembros de los Consejos de Justicia se viera envuelta en polémicas sobre el perfil político de los candidatos, con el daño consiguiente a la imagen de la Justicia (cuya primera consecuencia sería un mayor socavo de la misma, politizándola aun más y dando lugar a una visión del Poder Judicial sujeto a los intereses políticos autonómicos). Y es que la reforma facilita que las Comunidades Autónomas entren en esa dinámica de influencias políticas sobre el Poder Judicial, que hasta ahora sólo se ha producido en el ámbito estatal.

A nuestro juicio, los Estatutos de Autonomía no pueden atribuirse, como ha ocurrido en el presente caso, una competencia que constitucionalmente corresponde al Estado y salvo que se produzca una reforma constitucional ${ }^{44}$, de-

\footnotetext{
${ }^{44}$ En el mismo sentido puede leerse la propuesta sobre la federalización del Poder Judicial por parte de CÁMARA VILLAR, G., et alii, Por una reforma Federal del Estado Autonómico..., Op. Cit., p. 51-53, donde señala el autor después de afirmar que "un desarrollo federalizante del poder judicial en España precisaría, pues, de una reforma del texto constitucional" que "la federalización del poder judicial, contemplada arriba como tercera solución [se está refiriendo a lo expuesto en la p. 48, cuando señala que En otros casos, la primera instancia es servida por tribunales territoriales, con independencia del origen del derecho aplicable, mientras que las instancias superiores corresponden a tribunales de la federación, como ocurre en Alemania, Suiza y Australia], parece la alternativa más coherente con el deseo de avanzar en la territorialización del poder judicial de acuerdo con los principios federales. Una reforma constitucional en este sentido debería guiarse por los siguientes criterios: 1. Se mantendrían los principios generales sobre el
} 
ben limitarse, por su propia naturaleza, a regular los aspectos relativos a la "Administración de la Administración de Justicia”"45, pues solo a la Ley Orgánica del Poder Judicial le corresponde regular los aspectos relativos al Poder Judicial (Administración de Justicia en sentido estricto).

Quizás, a nuestro entender, habría que buscar otras soluciones y formas de integración entre el Poder Judicial y la realidad jurídico política del Estado de las Autonomías, en vez de empeñarse en influir directamente en las funciones de gobierno que tiene encomendadas el Consejo General del Poder Judicial en la Constitución.

Una solución intermedia, constitucionalmente aceptable, visto que a las Comunidades Autónomas no les es legítimo crear un Órgano de Gobierno

estatus constitucional y el ejercicio de la función jurisdiccional comunes a todos los miembros del poder judicial y a todos los órganos judiciales, tanto de las unidades federadas como de ámbito federal: apartados uno a cuatro del artículo 117 y artículo 127 CE. 2. La Constitución continuaría reservando a la legislación federal la regulación que diera un mínimo de unidad al ejercicio de la función jurisdiccional y a la organización del poder judicial en ambos ámbitos. 3. El Consejo General del Poder Judicial conservaría las funciones de garantía del estatus constitucional de los miembros del poder judicial, reservadas a la determinación del ingreso en el cuerpo y materia disciplinaria (potestad ésta que podría ser delegada). Las unidades federadas podrían participar, en su caso, en la designación de los miembros del Consejo General del Poder Judicial. 4. Se admitiría la posibilidad de crear poderes judiciales autónomos en las unidades federadas, a los que pertenecerían los órganos judiciales con competencia territorial sobre el territorio de aquellas o inferior y Jueces, Juezas, Magistradas y Magistrados que ejercieran sus funciones en dichos órganos. Igualmente, se admitiría la posibilidad de que existieran Consejos de Justicia del ámbito territorial federado con funciones relativas al gobierno del poder judicial correspondiente, así como mecanismos de coordinación entre estos y el Consejo General del Poder Judicial. 5. Las unidades federadas se responsabilizarían íntegramente de la gestión del poder judicial, incluido todo lo referente a los jueces, salvo lo atinente a su estatus constitucional."

${ }^{45}$ Es más, nos atrevemos a afirmar que bastante tenemos ya con la sutil interpretación del Tribunal Constitucional del artículo 149.1.5 CE, cuando en su sentencia 56/1990, FJ 6º diferenció entre Administración de fusticia en sentido estricto y Administración de la Administración de fusticia, pues no se entiende bien como es posible que tanto el Ejecutivo, como el Legislativo cuenten con autonomía suficiente para gestionar los medios personales y materiales que necesitan para el desarrollo de las funciones públicas que les asigna la Constitución y que por el contrario el Poder Judicial tenga que estar bajo la tutela y dependencia del Ejecutivo (Ministerio de Justicia y Consejerías de las Comunidades Autónomas). En este sentido puede leerse GARCÍA HERRERA, M. y LÓPEZ BASAGUREN, A. "Constitución y Poder Judicial la incompleta realización del Poder Judicial”, Estudios de derecho judicial, Núm. 90, 2006, p. 194 que señalan que“con ello, se opta por configurar un Poder Judicial que está constreñido a utilizar medios administrativos que dependen de poderes externos, bien sea el Ministerio de Justicia o las correspondientes Comunidades Autónomas con competencias en la materia. Y esto es algo absolutamente excepcional en relación con la realidad de otros poderes del Estado, como, muy relevantemente, el Poder Legislativo, en cuyo ámbito se considera, precisamente, que la autonomía administrativa, la disponibilidad de una administración propia bajo su exclusiva dependencia, es una consecuencia de su independencia." 
propio del Poder Judicial en su ámbito territorial, podría ser, que al igual que ocurre con la designación de Magistrados del Tribunal Constitucional por el Senado (artículo 184.7 del Reglamento del Senado), que las Comunidades Autónomas tuviesen una participación activa en la elección de los Vocales del CGPJ por parte de la Cámara Alta que cumpliría así su función de ser la Cámara de representación territorial (artículo 69.1 CE).

\section{GONGLUSIONES}

La regulación constitucional del Poder Judicial impide la existencia de órganos autonómicos del gobierno de Poder Judicial descentralizados, desvinculados o independientes del Consejo General, aunque no excluye que las potestades de gobierno del Poder Judicial se ejerzan de forma desconcentrada, pero, en todo caso, éstos órganos deben estar subordinados al Consejo General del Poder Judicial.

No obstante, pensamos que su creación por el legislador orgánico no debe considerarse con carácter prioritario, pues vendrían a sustituir el verdadero autogobierno de la Justicia (Salas de Gobierno de los Tribunales Superiores de Justicia) y su hipotética existencia no parece que vaya a resolver ningún problema, más bien al contrario, pues conlleva multiplicar por diecisiete el viciado esquema de LOPJ e implicaría llevar la politización del gobierno judicial, no ya a su órgano central, sino a cada una de las Comunidades Autónomas.

Quizás, a nuestro entender, haya que buscar otras soluciones y formas de integración entre el Poder Judicial y la realidad jurídico política del Estado de las Autonomías. Una solución intermedia, constitucionalmente aceptable, visto que a las Comunidades Autónomas no les es legítimo crear un órgano de gobierno propio del Poder Judicial en su ámbito territorial, sin perjuicio de que el legislador orgánico lo haga, podría ser que al igual que ocurre con la designación de Magistrados del Tribunal Constitucional por el Senado, que las Comunidades Autónomas tuviesen una participación activa en la elección de los Vocales del CGPJ por parte de la Cámara Alta que cumpliría así su función de ser la Cámara de representación territorial. 


\section{BIBLIOGRAFÍA}

AGIRREAZKUENAGA, I., "Modelos comparados de organización judicial y régimen de selección o elección de jueces y magistrados" Revista Poder fudicial, Núm. 75, 2004.

AGUDO ZAMORA, M., et alii, El Estatuto de Autonomía de Andalucía de 2007, Fundación Pública Andaluza Centro de Estudios Andaluces, 2008.

ÁLVAREZ CONDE, E. "El ámbito competencial del Consejo General del Poder Judicial y las Comunidades Autónomas" Revista del Centro de Estudios Constitucionales Núm. 16. Septiembre-diciembre 1993.

APARICIO PÉREZ, M. "Comentarios a la Sentencia 31/2010. Sobre el Poder Judicial.” Revista Catalana de dret públic, Núm. Especial Sentencia 31/2010 del Tribunal Constitucional, sobre el Estatuto de Autonomía de Cataluña 2006.

BALAGUER CALLEJÓN, F., et alii, El nuevo Estatuto de Andalucía, Tecnos, 2007.

BALLARÍN IRIBARREN, J., "Poder judicial y estado compuesto: el caso de los Estados Unidos" en MARIANO BAENA DEL ALCÁZZAR, et alii, Actualidad y perspectiva del derecho público a fines del siglo XX: homenaje al profesor Garrido Falla, Universidad Complutense, Madrid, 1992.

BALLESTER GARDELL, M., "Las reformas de los Estatutos de Autonomía y el Poder Judicial. La progresiva adaptación de la administración de justicia al estado de las autonomías" en FRANCISCO JAVIER GARCÍA ROCA, et alli, Treinta años de Constitución, Tirant lo Blanch, 2010.

BERLANGA RIBELLES, E. "El Gobierno del Poder Judicial. Consejo General y Consejos Territoriales", Estudios de derecho judicial, Núm. 90, 2006.

CABELLOS ESPIÉRREZ, M. A. "Poder Judicial y modelo de Estado en la Sentencia sobre el Estatuto de Autonomía de Cataluña." Revista Catalana de dret públic, Núm. Especial Sentencia 31/2010 del Tribunal Constitucional, sobre el Estatuto de Autonomía de Cataluña 2006.

CÁMARA VILLAR, G, "La descentralización del Gobierno del Poder Judicial y el proyecto de reforma de la LOPJ", Estudios de derecho judicial, Núm. 90, 2006. 
- et alii, Por una reforma Federal del Estado Autonómico, Fundación Alfonso Perales, 2012.

- "Reformas estatutarias y consejos de justicia autonómicos a la luz de la doctrina del Tribunal Constitucional" Teoría y realidad constitucional, Núm. 27, 2011.

CLAVERO ARÉVALO, M. "Andalucía veinticinco años del Estatuto de Autonomía" Administración de Andalucía: revista andaluza de administración pública, Núm. 1, 2003.

GRUZ VILLALÓN, P. y MEDINA GUERRERO, M., et alii, Comentarios al Estatuto de Autonomía para Andalucía, Centro de Publicaciones no Oficiales. Parlamento de Andalucía, Sevilla, 2012.

DEL RÍO MUÑOZ, F. "El Poder Judicial y reformas estatutarias. El nuevo Estatuto de Autonomía de Andalucía." Centro de Estudios Andaluces. Núm. 22.

GARGíA HERRERA, M. y LÓPEZ BASAGUREN, A. "Constitución y Poder Judicial la incompleta realización del Poder Judicial" Estudios de derecho judicial, Núm. 90, 2006.

GONZÁLEZ PÉREZ, J., "Los atentados al modelo de justicia de la Constitución de 1978" en Revista Española de Derecho Administrativo (REDA), Núm. 134, abril/junio 2007.

HERNÁNDEZ GÓMEZ, I. "Estatuto de Autonomía y Administración de Justicia en Canarias" Revista de la Facultad de Ciencias furídicas No 10/1, 2005/06.

LÓPEZ GUERRA, L., "El Poder Judicial y Comunidades Autónomas", en RODRÍGUEZ-ARANA, J., et alii, Curso de derecho público de las Comunidades Autónomas. Montecorvo, 2003.

LÓPEZ JIMÉNEZ, J. "Especial referencia a los Consejos Autonómicos de Justicia y su constitucionalidad. El CGPJ: pasado, presente y futuro del órgano de gobierno de la administración de justicia." El Derecho Editores, Base de Datos Bibliográfica, Furisprudencia, Furisdicción Derecho Administrativo. Julio 2008.

LUCAS MURILLO DE LA CUEVA, P. "El Poder Judicial en Andalucía." En SANTIAGO MUÑOZ MACHADO y MANUEL REBOLLO PUIG $e t$ alii, Comentarios al Estatuto de Autonomía para Andalucía. 
REQUERO IBÁÑEZ, J., "El Gobierno Judicial y el Consejo General del Poder Judicial" Fundación para el Análisis y Estudios Sociales. Papeles de la Fundación $\mathrm{N}^{\circ}$ 28, Madrid, 1996.

RUI VERDE, "El Poder judicial en las Constituciones de Portugal y España” Anuario de la Facultad de Derecho, Núm. 21, 2003.

SAIZ GARITAONANDIA, A., "Otras formas de gobierno en Estados compuesto. Los casos de Italia y los Estados Unidos de América." Revista Vasca de Administración Pública, Núm. 83, 2009.

TEROL BECERRA, M., et alii, Comentarios al Estatuto de autonomía para Andalucía, Tirant lo Blanch, Valencia, 2009.

VEGAS TORRES, J., "Consejos de Justicia y Justicia de Proximidad" Revista De derecho Procesal, 2006.

VIRGALA FORURIA, E. "El Poder Judicial en las Comunidades Autónomas" Estudios de Derecho Fudicial. Vol. 90, 2006.

XIOL RÍOS, J. "El Poder Judicial y su Consejo General en el Estado Social y Democrático de Derecho" Premios Poder Fudicial (I), CGPJ, 1986. 